Article

\title{
Connectedness to Nature and Public (Skin) Health Perspectives: Results of a Representative, Population-Based Survey among Austrian Residents
}

\author{
Daniela Haluza $^{1, *}$, Stana Simic ${ }^{2}$, Jan Höltge ${ }^{1}$, Renate Cervinka ${ }^{1}$ and Hanns Moshammer ${ }^{1}$ \\ 1 Institute of Environmental Health, Center for Public Health, Medical University of Vienna, \\ Kinderspitalgasse 15, A-1090 Vienna, Austria; E-Mails: janhoeltge@gmx.de (J.H.); \\ renate.cervinka@meduniwien.ac.at (R.C.); hanns.moshammer@meduniwien.ac.at (H.M.) \\ 2 Institute of Meteorology, University of Natural Resources and Life Sciences, Vienna, \\ Peter-Jordan-Straße 82, A-1190 Vienna, Austria; E-Mail: stana.simic@boku.ac.at
}

* Author to whom correspondence should be addressed; E-Mail: daniela.haluza@meduniwien.ac.at; Tel.: +43-1-401-603-4933; Fax: +43-1-401-609-34903.

Received: 12 October 2013; in revised form: 13 January 2014 / Accepted: 13 January 2014 / Published: 20 January 2014

\begin{abstract}
Connectedness to nature $(\mathrm{CN})$ influences motivation to have contact with outdoor natural environments. Spending leisure time in natural environments is beneficial for human health and well-being. Besides these positive effects, health risks of open-air activities are mainly related to unprotected sun light exposure-associated acute and chronic skin hazards. Thus, we conducted a cross-sectional, representative telephone survey among Austrian residents to study the association of perceived $\mathrm{CN}$ level with sun-exposure knowledge, tanning habits, and sun protective behaviour. In total, 1,500 study subjects (50.5\% females) participated in this questionnaire survey. Although knowledge about tanning and motives to tan were similar among genders, females performed more photoprotective measures and were more connected to nature (all $p<0.001$ ) compared to males. Older age and outdoor sport were significant gender-independent predictor variables influencing perceived $\mathrm{CN}$ level. Additionally, level of education was relevant in male $\mathrm{CN}$, whereas non-smoking and higher knowledge were predictive of female $\mathrm{CN}$. This survey provides so far unreported empirical data on the relationship between nature connectedness and skin health-relevant recreational habits of Austrian residents. The findings suggest to
\end{abstract}


integrate hitherto neglected gender-specific Public (Skin) Health promotion when counselling on the manifold health advantages of outdoor activities.

Keywords: melanoma; skin cancer prevention; gender differences; connectedness to nature; questionnaire survey; Public Health

\section{Introduction}

Contact with nature and its inherent biodiversity is vital for human beings on the level of all three health dimensions - physical, mental and social well-being and health. Advantageous health effects of spending leisure time outdoors have been constantly reported by various scientific domains. Environmental psychology-based research assessed positive effects of natural surroundings on restoration by means of measuring physiological (e.g., cortisol levels) and psychological (e.g., mood) parameters [1]. Moreover, several investigations reported positive associations between amount of natural environments and health benefits $[2,3]$. On the other hand, enhancement of physical activity through natural environments and subsequent benefits for fitness and body weight was scope of Public Health-related research. Therein, authors concluded that compared to indoor exercise, outdoor activities have greater positive effects on physical and mental well-being [4-6].

Besides environmental hazards such as vector-borne diseases, noise and ambient air pollutants including particulate matter and pollen, disadvantages of open-air activities are mostly associated with harmful health effects related to ultraviolet (UV) light [7-9]. Intermittent sun exposure patterns as experienced in outdoor abidance for recreational purposes are a well-known risk factors for the development of melanoma, the deadliest form of skin cancer [10]. Increasing melanoma incidence and mortality rates are an important global health issue with vast economic burden [11-13]. Furthermore, solar radiation causes deterioration of physical attractiveness by means of skin aging as well as development of nevi and pigmentary abnormalities with limited clinical significance [14]. Other related adverse outcomes comprise various non-dermatological effects such as the ophthalmologic disorders cataract, pterygium, and maculopathy [15].

Effective use of photoprotective measures including consistently applying proper amounts of sunscreen and wearing sunglasses could prevent health-threatening outcomes of lifestyle-associated sunlight exposure [16]. Also, a shift of melanoma primary body sites from head and neck to the chest in recent years points towards modifications in intentional sun exposure driven by age and gender-related fashion trends and tanning behaviour changes [17]. Thus, getting deeper insight into common health beliefs and motives affecting the success of health promotion campaigns is relevant for decision makers, medical professionals, consumers, and patients. In this context, in recently published papers, we have introduced the wording Public (Skin) Health as an umbrella term for respective Public Health efforts focusing on potential risks of solar radiation exposure [18,19].

In recent decades, the construct of connectedness to nature $(\mathrm{CN})$, which is very similar to nature relatedness, has been increasingly used to assess personal characteristics that influence emotional bonds with outdoor natural environments and pro-environmental habits [20]. Moreover, nature connectedness seems to be a character trait that is relatively stable over time, differs among individuals 
and influences behavior [21,22]. In accordance with this conceptual approach, people with higher CN levels show more motivation to seek contact to natural spaces than people with low CN $[23,24]$. Thus, from a Public (Skin) Health perspective and in synopsis with epidemiological knowledge on sunlight-associated skin diseases, $\mathrm{CN}$ could be seen as risky health behaviour that stimulates a lifestyle with frequent outdoor leisure time activities.

So far, empirical data on the connection between $\mathrm{CN}$ and outdoor sun exposure-related habits are missing. Thus, aim of the present population-based telephone survey was to analyze how perceived $\mathrm{CN}$ interacts with sun exposure knowledge, motives to tan, and sun protective behaviours of a cross section of Austrian residents. Additionally, data analysis focussed on gender specificity to provide practical implications for developing target group appropriate strategies for national Public (Skin) Health promotion.

\section{Methods}

\subsection{Data Collection}

The present study was part of the transdisciplinary research project "UVSkinRisk", approved by the local ethical committee of the Medical University Vienna, Austria (EK662_2010) and conducted in accordance with the principles of the International Declaration of Helsinki [25].

We contracted the independent ISO-certified company Triconsult (Vienna, Austria) to realize a nationwide telephone survey. Data were collected from 3 to 17 August 2011 among Austrian residents aged between 18 and 74 years. To acquire a gender-balanced sample, we did not include the age group 75+ in our analysis due to a biased gender distribution. A random sample of 20,000 telephone numbers representative for the Austrian population by means of age and place of residence was draw from the official national telephone directory list. Until the predisposed number of 1,500 completed interviews was reached, about 11,100 individuals refused study contribution due to unknown reasons. Participation was voluntarily and anonymous. Verbal consent was obtained before start of the interview which was completed in about 10 to $12 \mathrm{~min}$. Survey questionnaire design and software assistance prevented item non-response and missing data [26]. Participants reported on socio-demographic characteristics (age, gender as well as highest education categorized into the (school) levels primary, secondary, and tertiary (i.e., high school/university) and classified their pigmentary phototype (skin types I-VI according to the Fitzpatrick Scale) [27]. Further, study subjects provided information on sunbed use, outdoor sunbathing, predominantly used sun protection factor (SPF) value, occurrence of sunburns (in the last year and in childhood), current tobacco smoking habits (categorized into never smokers, ex-smokers, and smokers), and vigorous outdoor sport activities.

To measure participants baseline knowledge of important skin health risks, we used achievement in a test of five true-false questions that basically tested knowledge related to UV light exposure, skin cancer, and sun protective behaviour, adapted from the literature [18,28,29]. Numbers of correct responses were summed to generate the covariate "knowledge score" with a highest achievable score of five correct answers.

Further, we assessed frequency of eight recommended sun protective habits (basically: "For sun protection I use sunscreen (min. SPF 15)/reapply sunscreen during the day/reapply sunscreen after swimming/avoid midday sun/seek shade/wear a hat/wear protective garments/wear sunglasses.") using 
a 5-point Likert scale scoring from "always" $(=1)$ to "never" $(=5)$ adapted from the literature $[18,30]$. To generate a scale on sun protection, we comprising these eight items showing an acceptable internal consistency (Cronbach's alpha: 0.73). For building the covariate "sun protection", we summed the set of scores and calculated mean of these eight items.

Respondents were requested to rate their degree of agreement with eight statements related to perceived motives to tan (basically: "A tanned skin is desirable because it enhances sex appeal/enhances attractiveness/enhances self-confidence/enhances fitness/enhances body shape/reduces paleness/reduces acne/reduces stretch marks.") using a 5-point Likert scale scoring from "strongly agree" (=1) to "strongly disagree" (=5). For building a scale, we combined these eight items, showing an acceptable internal consistency (Cronbach's alpha: 0.64). In order to generate the covariate "motives to tan", we summed the set of scores and calculated the mean of these eight items.

In our previously published validation study among an Austria study sample, we showed a high correlation between the scale and the single item for $\mathrm{CN}$ assessment [24]. Accordingly, to evaluate personal disposition relevant for environment-related human health behavior in the current survey, we solely employed the single-item version to operationalize nature connectedness, using the eleven-step rating question "How would you rate your connectedness to nature?" ranging from "none" $(=0)$ to "very high" (=10).

\subsection{Statistical Data Analysis}

The collected data were statistically processed using EXCEL database (Microsoft, Seattle, WA, USA) and SPSS Version 17.0 (SPSS Inc., Chicago, IL, USA). For all statistical analyses, two-sided level of significance was set at $p=0.05$. Data were expressed as proportions, means, and standard deviation (SD) values where appropriate. Also, we used median split to obtain dichotomized subgroups of study subjects with more or less pronounced personal attributes, according to similar evaluations $[31,32]$. Thus, we separated the knowledge score, the scales (sun protection and motives to tan), and the single item question evaluating $\mathrm{CN}$ at cut point of $\leq$ or $>$ than the median (low/high, respectively). Pearson $\mathrm{Chi}^{2}$ tests and Mann Whitney $\mathrm{U}$ tests were used to analyze group differences for gender (male/female) and CN (low/high).

Further, we studied the influence of predictor variables comprising socio-demographic characteristics and skin health-related aspects on CN (low/high). Using logistic regression analysis, we assessed homogeneity of demographic factors including age group (in years, younger ages vs. 60+), educational level (non-tertiary vs. tertiary), skin type (fair vs. moderate-dark), as well as smoking habits (non-smoker vs. smoker), SPF value (non vs. higher values), sport activities, sunbed use, sunburns (all: yes vs. no), sunbathing (never vs. more often), as well as knowledge score, sun protection and motives to tan (all: low vs. high) between study subject with low and high $\mathrm{CN}$, respectively. To control for confounding, we calculated both crude (simple regression model) and adjusted (multiple regression model) odds ratios (OR) and 95\% confidence intervals (CI) for both genders. As suggested by Koster et al., we only considered factors with a statistically significant difference in distribution of adjusted models as possible explanations [33]. 


\section{Results}

In total, 1,500 Austrian study subjects (18-74 years, mean 44.7 years, SD 15.4) participated in this cross-sectional survey. As we intended to acquire a gender-balanced sample, merely slightly more females than males $(50.5 \%$ vs. $49.5 \%$, respectively) completed the questionnaire-based telephone interview.

As depicted in part I of Table 1, 33.7\% of respondents reported that they did not sunbathe in 2010 . We found significant gender differences as compared to males more females $(p=0.02)$ denied sunbathing activities. Notably and despite these differences, male and female participants did not differ significantly regarding self-reported amount of sunburns both in the last year $(p=0.17)$ and in childhood $(p=0.37)$. Nevertheless, $31 \%$ of participants $(33 \%$ of males and $28 \%$ of females, respectively) reported at least one case of sunburn in the last year. Moreover, 1115 subjects (74\%, 76\% of males and about $72 \%$ of female, respectively) experienced sunburns in childhood. For participants who self-reported habitual outdoor tanning activities, we characterized frequency and duration of this behavior (Table 1, part II). Although we did not reveal gender differences regarding frequency $(p=0.108)$, compared to females, males were more likely to spend more time in the sun in general $(p=0.024)$ and during peak sun hours (from 11 am until 4 pm, $p=0.029$ ).

Further, Table 2 provides an overview of overall and gender-specific distributions of responses to the $\mathrm{CN}$-single item. Corresponding to median of respective item responses, factors were dichotomized (low/high) to generate subgroups $(\mathrm{CN}$ : low: 0-7, high: 8-10; none $=0$, very high $=10$; knowledge score: low: $0-4$, high: $4-7$; weak knowledge $=0$, full knowledge $=7$; motives to tan: low: $0-4$, high: 4-5; fully agree $=1$, fully disagree $=5$; and sun protection: low: $0-3$, high: $3-5$; very frequently $=1$, never $=5$ ). As presented in Table 3, males and females did not differ regarding achievement in the knowledge test and amount of agreement with motives to tan. In contrast, we revealed significant gender differences $(p<0.0001)$ in amount of performed photoprotective behaviours and overall nature connectedness. More specifically, $63.2 \%$ of male study subjects compared to $73.4 \%$ of female participants reported high $\mathrm{CN}$.

As a further step, we compared low and high $\mathrm{CN}$ specifications in regard of sample characteristics (Table 4). Whereas reported amount of motives to tan and performed sun protective behaviours did not significantly differ among CN subgroups, we found differences in knowledge score $(p=0.007)$, occurrence of sunburn $2010(p=0.003)$, and outdoor sport activity $(p<0.0001)$. Additionally, participants with distinct smoking habits significantly differed in their $\mathrm{CN}(p<0.0001)$, as $20 \%$ of smokers, $21 \%$ of ex-smokers, and $60 \%$ of non-smokers reported to be highly connected to nature.

Next, we investigated gender-specific possible predictor variables for $\mathrm{CN}$ subgroups (Table 5). As only $0.3 \%$ of participants were assigned to skin type VI, we consolidated skin types V and VI for multiple regression analysis. In our adjusted regression models (male/female model, respectively: log-likelihood $=916.973 / 803.490$, Cox and Snell $R^{2}=0.077 / 0.095$, chi $^{2}=59.261 / 75.392$, both models: $d f=4, p<0.0001$ ), increasing age (analyzed by age groups), and sport activities (males: OR $=1.42$, $95 \% \mathrm{CI}=1.01-1.99$; females: $\mathrm{OR}=2.05,95 \% \mathrm{CI}=1.43-2.93)$ significantly influenced perceived level of CN gender-independently. 
Table 1. Gender differences of (part I) reported sunburns and sunbaths as well as (part II) frequency and duration of outdoor tanning activities.

\begin{tabular}{|c|c|c|c|c|c|c|}
\hline \multirow{2}{*}{ Factors } & \multicolumn{2}{|c|}{ Males } & \multicolumn{2}{|c|}{ Females } & \multicolumn{2}{|c|}{ Total } \\
\hline & $n$ & $\%$ & $n$ & $\%$ & $n$ & $\%$ \\
\hline Part I. Total & 742 & 100 & 758 & 100 & 1,500 & 100 \\
\hline \multicolumn{7}{|c|}{ Sunburns $2010 ; \mathrm{n} /$ year $^{\mathrm{a}}$} \\
\hline Never & 495 & 66.7 & 544 & 71.8 & 1,039 & 69.3 \\
\hline $1-2$ & 216 & 29.1 & 183 & 24.1 & 399 & 26.6 \\
\hline $3-5$ & 28 & 3.8 & 29 & 3.8 & 57 & 3.8 \\
\hline $6-10$ & 3 & 0.4 & 2 & 0.3 & 5 & 0.3 \\
\hline$p$ & 0.170 & & & & & \\
\hline \multicolumn{7}{|c|}{ Sunburns in childhood; $\mathrm{n}^{\mathrm{b}}$} \\
\hline Never & 176 & 23.7 & 209 & 27.6 & 385 & 25.7 \\
\hline $1-2$ & 213 & 28.7 & 213 & 28.1 & 426 & 28.4 \\
\hline $3-5$ & 201 & 27.1 & 188 & 24.8 & 389 & 25.9 \\
\hline $6-10$ & 152 & 20.5 & 148 & 19.5 & 300 & 20.0 \\
\hline $\mathrm{p}$ & .370 & & & & & \\
\hline \multicolumn{7}{|l|}{ Sunbaths $2010^{c}$} \\
\hline Yes & 513 & 69.1 & 481 & 63.5 & 994 & 66.3 \\
\hline No & 229 & 30.9 & 277 & 36.5 & 506 & 33.7 \\
\hline $\mathrm{p}$ & $0.020 *$ & & & & & \\
\hline Part II. Total & 513 & 100 & 481 & 100 & 994 & 100 \\
\hline \multicolumn{7}{|c|}{ Frequency; days ${ }^{\mathrm{d}}$} \\
\hline $1-5$ & 157 & 30.6 & 130 & 27.0 & 287 & 28.9 \\
\hline $6-15$ & 148 & 28.8 & 154 & 32.0 & 302 & 30.4 \\
\hline $16-30$ & 128 & 25.0 & 126 & 26.2 & 254 & 25.6 \\
\hline$>30$ & 80 & 15.6 & 71 & 14.8 & 151 & 15.2 \\
\hline $\mathrm{p}$ & 0.108 & & & & & \\
\hline \multicolumn{7}{|c|}{ Duration; hours ${ }^{\mathrm{e}}$} \\
\hline$<0.5$ & 95 & 18.5 & 109 & 22.7 & 204 & 20.5 \\
\hline $0.5-1$ & 115 & 22.4 & 112 & 23.3 & 227 & 22.8 \\
\hline $1-3$ & 172 & 33.5 & 165 & 34.3 & 337 & 33.9 \\
\hline$>3$ & 131 & 25.5 & 95 & 19.8 & 226 & 22.7 \\
\hline $\mathrm{p}$ & $0.024 *$ & & & & & \\
\hline \multicolumn{7}{|c|}{ During midday hours; hours ${ }^{\mathrm{f}}$} \\
\hline Never & 71 & 13.8 & 90 & 18.7 & 161 & 16.2 \\
\hline$<1$ & 155 & 30.2 & 140 & 29.1 & 295 & 29.7 \\
\hline $1-2$ & 140 & 27.3 & 140 & 29.1 & 280 & 28.2 \\
\hline $2-4$ & 90 & 17.5 & 70 & 14.6 & 160 & 16.1 \\
\hline$>4$ & 57 & 11.1 & 41 & 8.5 & 98 & 9.9 \\
\hline $\mathrm{p}$ & $0.029 *$ & & & & & \\
\hline
\end{tabular}

\footnotetext{
${ }^{a}$ In the past year, how many times did you receive a sunburn? ${ }^{b}$ In your childhood, how many times did you receive a sunburn? ${ }^{\mathrm{c}}$ In the past year, did you usually sunbath outdoors on a sunny day? ${ }^{\mathrm{d}}$ In the past year, how many days did you sunbath outdoors? ${ }^{\mathrm{e}}$ In the past year, how long did you sunbath outdoors on a sunny day? ${ }^{\mathrm{f}}$ In the past year, how often did you sunbath outdoors during midday hours? $* p<0.05$ from $\mathrm{Chi}^{2}$ tests (males vs. females).
} 
Table 2. Gender-specific distribution of responses to the question "How would you rate your connectedness to nature?" $(\mathrm{CN})$ ranging from "none" $(=0)$ to "very high" $(=10)$.

\begin{tabular}{ccccccc}
\hline CN & \multicolumn{2}{c}{ Males } & \multicolumn{2}{c}{ Females } & \multicolumn{2}{c}{ Total } \\
\cline { 2 - 7 } & $\boldsymbol{n}$ & $\mathbf{\%}$ & $\boldsymbol{n}$ & $\mathbf{\%}$ & $\boldsymbol{n}$ & $\mathbf{\%}$ \\
\hline Total & 742 & 100 & 758 & 100 & 1,500 & 100 \\
0 (none) & 2 & 0.3 & 2 & 0.3 & 4 & 0.3 \\
1 & 2 & 0.3 & 2 & 0.3 & 4 & 0.3 \\
2 & 7 & 0.9 & 4 & 0.5 & 11 & 0.7 \\
3 & 8 & 1.1 & 1 & 0.1 & 9 & 0.6 \\
4 & 14 & 1.9 & 8 & 1.1 & 22 & 1.5 \\
5 & 80 & 10.8 & 61 & 8.0 & 141 & 9.4 \\
6 & 41 & 5.5 & 38 & 5.0 & 79 & 5.3 \\
7 & 119 & 16.0 & 86 & 11.3 & 205 & 13.7 \\
8 & 176 & 23.7 & 197 & 26.0 & 373 & 24.9 \\
9 & 84 & 11.3 & 88 & 11.6 & 172 & 11.5 \\
10 (very high) & 209 & 28.2 & 271 & 35.8 & 480 & 32.0 \\
\hline
\end{tabular}

Table 3. Gender differences regarding factor specifications of connectedness to nature (low/high $\mathrm{CN}$ ), knowledge score, motives to tan, and sun protection.

\begin{tabular}{|c|c|c|c|c|c|c|}
\hline Factors & Mean ${ }^{1}$ & SD & Median & Low; $n(\%)^{2}$ & High; $n(\%)$ & Total; $n(\%)$ \\
\hline \multicolumn{7}{|l|}{$\mathrm{CN}^{\mathrm{a}}$} \\
\hline Males & 7.86 & 1.95 & 8 & $273(36.8)$ & $469(63.2)$ & $742(100)$ \\
\hline Females & 8.26 & 1.79 & 8 & $202(26.6)$ & $556(73.4)$ & $758(100)$ \\
\hline$p$ & $0.0001 *$ & \multicolumn{5}{|c|}{$0.0001 *$} \\
\hline Total & 8.06 & 1.88 & 8 & 475 (31.7) & $1,025(68.3)$ & $1,500(100)$ \\
\hline \multicolumn{7}{|c|}{ Knowledge score ${ }^{\mathrm{b}}$} \\
\hline Males & 4.28 & 1.2 & 4 & $158(21.3)$ & $584(78.7)$ & $742(100)$ \\
\hline Females & 4.32 & 1.1 & 4 & $161(21.2)$ & $597(78.8)$ & $758(100)$ \\
\hline$p$ & 0.550 & \multicolumn{5}{|c|}{0.980} \\
\hline Total & 4.3 & 1.14 & 4 & $319(21.3)$ & $1,181(78.7)$ & $1,500(100)$ \\
\hline \multicolumn{7}{|c|}{ Motives to $\tan ^{c}$} \\
\hline Males & 3.86 & 0.84 & 4 & $404(54.4)$ & 338 (45.6) & $742(100)$ \\
\hline Females & 3.78 & 0.91 & 3.9 & $434(57.3)$ & 324 (42.7) & $758(100)$ \\
\hline$p$ & 0.082 & \multicolumn{5}{|c|}{0.273} \\
\hline Total & 3.82 & 0.88 & 4 & 838 (55.9) & $662(44.1)$ & $1,500(100)$ \\
\hline \multicolumn{7}{|c|}{ Sun protection ${ }^{\mathrm{d}}$} \\
\hline Males & 3.1 & 0.82 & 3.1 & $364(49.1)$ & 378 (50.9) & $742(100)$ \\
\hline Females & 2.86 & 0.795 & 2.9 & $464(61.2)$ & $294(38.8)$ & $758(100)$ \\
\hline$p$ & $0.0001 *$ & \multicolumn{5}{|c|}{$0.0001 *$} \\
\hline Total & 2.98 & 0.82 & 3.0 & $828(55.2)$ & $672(44.8)$ & $1,500(100)$ \\
\hline
\end{tabular}


Table 4. Differences in sample characteristics regarding specifications of connectedness to nature $(\mathrm{CN}$, low/high).

\begin{tabular}{|c|c|c|c|c|c|c|}
\hline \multirow{2}{*}{ Factors } & \multicolumn{2}{|c|}{ Low CN } & \multicolumn{2}{|c|}{ High CN } & \multicolumn{2}{|c|}{ Total } \\
\hline & $n$ & $\%$ & $n$ & $\%$ & $n$ & $\%$ \\
\hline Total & 475 & 100 & 1025 & 100 & 1500 & 100 \\
\hline \multicolumn{7}{|l|}{ Smoking $^{\text {a }}$} \\
\hline Non-smoker & 231 & 48.6 & 610 & 59.5 & 841 & 56.1 \\
\hline Ex-smoker & 100 & 21.1 & 213 & 20.8 & 313 & 20.9 \\
\hline Smoker & 144 & 30.3 & 202 & 19.7 & 346 & 23.1 \\
\hline$p$ & $0.0001 *$ & & & & & \\
\hline \multicolumn{7}{|l|}{ Sport activity ${ }^{b}$} \\
\hline Yes & 264 & 55.6 & 678 & 66.1 & 942 & 62.8 \\
\hline No & 211 & 44.4 & 347 & 33.9 & 558 & 37.2 \\
\hline$p$ & $0.0001 * *$ & & & & & \\
\hline \multicolumn{7}{|l|}{ Sunburn $2010^{c}$} \\
\hline Yes & 171 & 36.0 & 290 & 28.3 & 461 & 30.7 \\
\hline No & 304 & 64.0 & 735 & 71.7 & 1039 & 69.3 \\
\hline$p$ & $0.003 *$ & & & & & \\
\hline \multicolumn{7}{|c|}{ Knowledge score } \\
\hline low & 121 & 25.5 & 198 & 19.3 & 319 & 21.3 \\
\hline high & 354 & 74.5 & 827 & 80.7 & 1181 & 78.7 \\
\hline$p$ & $0.007 *$ & & & & & \\
\hline \multicolumn{7}{|l|}{ Motives to tan } \\
\hline low & 244 & 51.4 & 488 & 47.6 & 732 & 48.8 \\
\hline high & 231 & 48.6 & 537 & 52.4 & 768 & 51.2 \\
\hline$p$ & 0.183 & & & & & \\
\hline \multicolumn{7}{|l|}{ Sun protection } \\
\hline low & 214 & 45.1 & 508 & 49.6 & 722 & 48.1 \\
\hline high & 261 & 54.9 & 517 & 50.4 & 778 & 51.9 \\
\hline$p$ & 0.104 & & & & & \\
\hline
\end{tabular}

${ }^{\mathrm{a}}$ Do you smoke or have you ever smoked cigarettes? ${ }^{\mathrm{b}}$ Do you usually do outdoor sports? ${ }^{\mathrm{c}}$ In the past year, did you receive a sunburn? $* p<0.05$ and $* * p \leq 0.001$ from $\mathrm{Chi}^{2}$ tests (low $v s$. high).

Table 5. Logistic regression analysis of factors affecting $\mathrm{CN}$ after median split (low $\mathrm{CN}$ : 0-7, high CN: 8-10), stratified by gender.

\begin{tabular}{|c|c|c|c|c|c|c|c|c|c|c|}
\hline \multirow[b]{2}{*}{ Factors } & \multicolumn{6}{|c|}{ Males OR (CI 95\%) } & \multicolumn{4}{|c|}{ Females OR (CI 95\%) } \\
\hline & $n$ & \multicolumn{2}{|l|}{ Adjusted $^{1}$} & \multicolumn{2}{|l|}{ Crude } & $n$ & \multicolumn{2}{|l|}{ Adjusted $^{2}$} & \multicolumn{2}{|l|}{ Crude } \\
\hline Total & 742 & & & & & 758 & & & & \\
\hline Age; years & & & $*$ & & $* *$ & & & $*$ & & $* *$ \\
\hline $18-29$ & 160 & $1=\operatorname{Ref}$ & & $1=\operatorname{Ref}$ & & 145 & $1=\operatorname{Ref}$ & & $1=\operatorname{Ref}$ & \\
\hline $30-39$ & 143 & $2.1(1.3-3.5)$ & $*$ & $2.3(1.5-3.7)$ & $* *$ & 135 & $1.5(0.9-2.6)$ & & $1.7(1.1-2.9)$ & $*$ \\
\hline $40-49$ & 173 & $2.4(1.5-3.8)$ & $* *$ & $2.6(1.6-4.0)$ & $* *$ & 167 & $2.3(1.3-4.0)$ & $*$ & $2.7(1.6-4.4)$ & $* *$ \\
\hline $50-59$ & 126 & $2.6(1.5-4.5)$ & $* *$ & $2.7(1.6-4.4)$ & $* *$ & 134 & $2.0(1 .-3.6)$ & $*$ & $2.6(1.5-4.3)$ & $* *$ \\
\hline $60-74$ & 140 & $1.8(1.0-3.0)$ & $*$ & $1.8(1.1-2.8)$ & $*$ & 177 & $1.8(1.0-3.3)$ & & $2.5(1.5-4.1)$ & $* *$ \\
\hline Educationa & vel & & $*$ & & $*$ & & & & & $*$ \\
\hline Primary & 168 & $1.5(1.0-2.4)$ & $*$ & $1.4(1.0-2.1)$ & $*$ & 189 & $1.3(0.8-2.2)$ & & $1.7(1.1-2.7)$ & $*$ \\
\hline Secondary & 320 & $1.5(1.1-2.2)$ & $*$ & $1.5(1.1-2.1)$ & & 386 & $1.4(0.9-2.1)$ & & $1.5(1.1-2.3)$ & $*$ \\
\hline Tertiary & 254 & $1=\operatorname{Ref}$ & & $1=\operatorname{Ref}$ & & 183 & $1=\operatorname{Ref}$ & & $1=\operatorname{Ref}$ & \\
\hline
\end{tabular}


Table 5. Cont.

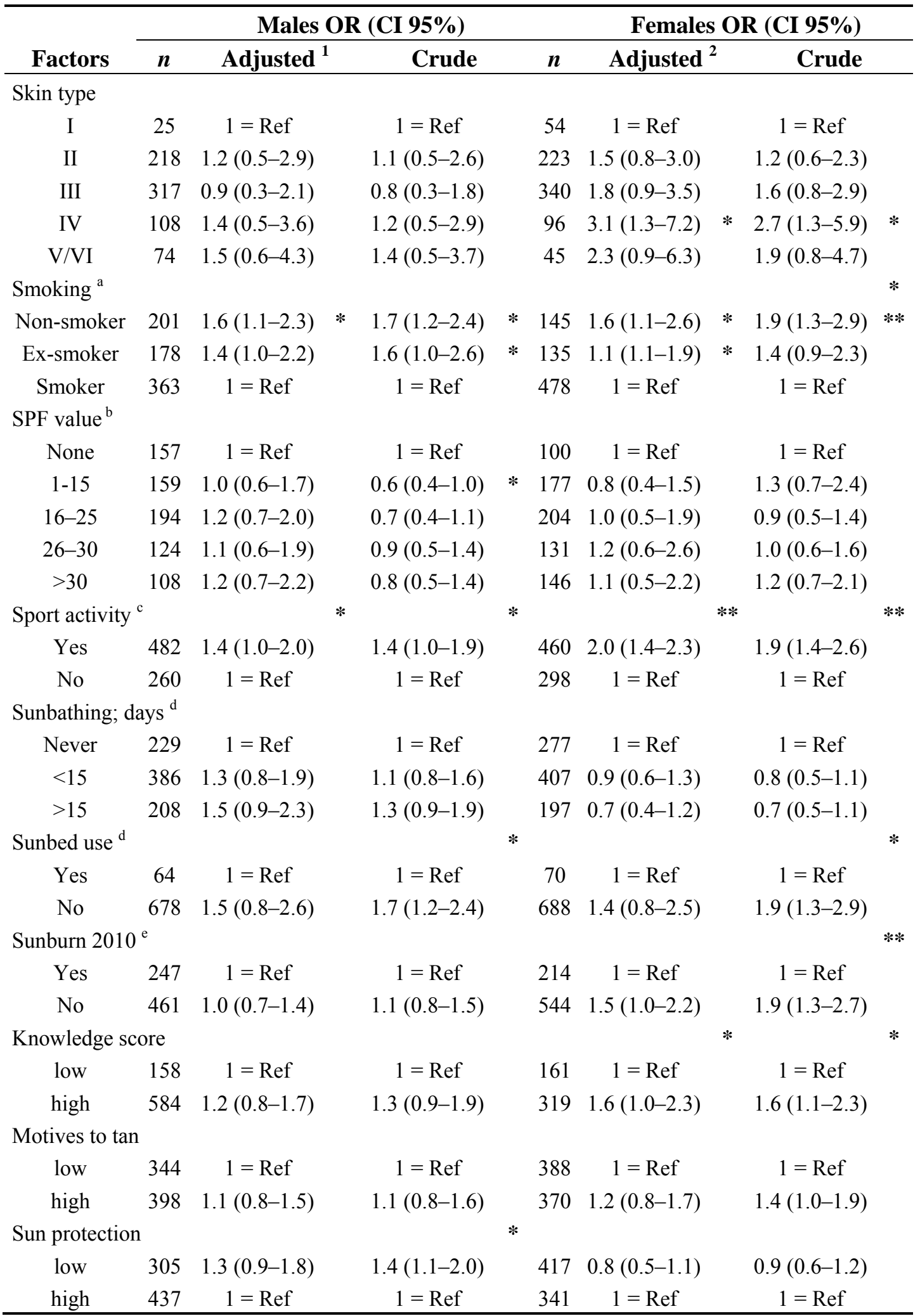

a "Do you smoke or have you ever smoked cigarettes?" b "What is the SPF value of the sunscreen you are usually using?" c "Do you usually do outdoor sports?" d "In the past year, how often did you sunbath outdoors?" "In general, do you use sunbeds?" e "In the past year, how many times did you receive a sunburn?" ${ }^{1} \log$-likelihood $=916.973$, Cox and Snell $\mathrm{R}^{2}=0.077, \mathrm{chi}^{2}=59.261, \mathrm{df}=4, p<0.0001{ }^{2}{ }^{2} \log$ likelihood $=803.490$, Cox and Snell $\mathrm{R}^{2}=0.095, \mathrm{chi}^{2}=75.392, \mathrm{df}=4, p<0.0001 ; * p<0.05, * * p \leq 0.001$. 
Further, educational level was a relevant factor for $\mathrm{CN}$ of male study subjects (primary education: $\mathrm{OR}=1.5,95 \% \mathrm{CI}=1.0-2.4$; secondary education: $\mathrm{OR}=1.5,95 \% \mathrm{CI}=1.1-2.2$ ), whereas smoking habits (non-smoking: $\mathrm{OR}=1.6,95 \% \mathrm{CI}=1.1-2.6$; ex-smoking: $\mathrm{OR}=1.1,95 \% \mathrm{CI}=1.1-1.9$ ) and knowledge $(\mathrm{OR}=1.6,95 \% \mathrm{CI}=1.0-2.3)$ predicted $\mathrm{CN}$ of females.

\section{Discussion}

The present cross-sectional study aimed at providing so far lacking empirical insight into lifestyle habits influencing recreational exposure to outdoor UV radiation. Thus, we conducted telephone interviews among a sample ( $n=1,500,50.5 \%$ females) representative of the Austrian socio-demographic population in terms of age and place of residence.

In line with previously published research, we herein confirmed evidence for gender differences concerning leisure sun protective and exposure behaviour [34-37]. In our sample, males compared to females were more likely to spent time in the sun $(p<0.05)$ and reported on using less photoprotective measures such as sunscreen $(p<0.0001)$.

Moreover, overall sun exposure-related knowledge reached quite satisfactory levels among both genders, with as many as $79 \%$ of study subjects achieving a high knowledge score. Nevertheless, it seems that this knowledge has not been put into execution: nearly one third of study subjects suffered from sunburn in 2010 and even about three quarters reported childhood sunburns. These are alarmingly high percentages as it is evident that a brief, intense sun exposure pattern resulting in blistering sunburn rather than years of tanning might cause melanoma [38]. However, in addition to behavioural aspects, genetic factors such as a family disposition, multiple nevi, and skin type could influence one individual's melanoma risk [39]. In addition to early diagnosis of skin lesions, reducing the amount of blistering sunburns are the most important means to challenge worldwide rising melanoma incidence and mortality rates [40]. Our study findings suggest that on the one hand previous Public (Skin) Health campaigns effectively transported educative information to the Austrian population (high knowledge). On the other hand, there is still an urgent need to further increase health risk awareness of unprotected sun exposure, achievable by, e.g., public melanoma prevention campaigns [19].

Nature connectedness was consistently associated with emotional dimensions of experiences in nature environments and associated feelings of mindfulness and eudemonic aspects of well-being $[24,41]$. As a possible explanation, contact to nature perhaps provokes and enhances physical health which, consecutively, could increase mental well-being or vice versa. Thus, we analyzed the relationship between $\mathrm{CN}$ level and spending leisure time outdoors for recreational tanning behaviour and sport activities. Common tools to assess emotional bondages with outdoor environments are constantly advanced and refined [22,42]. Established measures suitable for evaluating relatedness to nature include a scale and a single-item version to operationalize CN. Short-form versions of pre-existing $\mathrm{CN}$ scales were reliable measurement tools in other related studies [43]. Accordingly, based on a previous study that reported a high correlation between the scale and the single item, we used the latter to assess $\mathrm{CN}$ [24]. Advantages of this measure included the possibility to explore the concept of $\mathrm{CN}$ fast and easily as well as the unbiased neutral wording.

Generally, $27 \%$ of males and $19 \%$ of females were tobacco smokers. These findings correlate exactly with previously published smoking rates, indicating high reproducibility of smoking incidence 
data in Austria [44]. In addition to what this survey adds to skin health-related aspects, we found so far unreported associations of $\mathrm{CN}$ with current tobacco consuming habits. In order to potentially reveal new aspects of inducing behavioural modifications, future research could address the question why smokers were less connected to nature ( $p<0.0001$, Table 4 ). In our population-based sample, $30 \%$ of participants with low $\mathrm{CN}$ levels smoked, whereas regarding high $\mathrm{CN}, 20 \%$ of study subjects were smokers, $21 \%$ ex-, and $60 \%$ non-smokers. This finding was unexpected as to date, in contrast to indoor premises smoking in outdoor environments including parks and urban green spaces has not yet been regulated by Austrian law. However, from a Public Health perspective, a legal smoking ban would be favourable regarding smoking cessation encouragement and second-hand smoke exposure reduction [45]. Additionally, a smoking stop could directly improve health-related quality of life [46].

Further, we confirmed recently reported observations regarding the impact of socio-demographic characteristics on CN. We found an overall significant impact of both age (young vs. older age) and gender (females vs. males) [47]. In our survey, compared to people reporting low CN, more study participants reporting high $\mathrm{CN}$ performed outdoor sport activities $(p<0.0001)$. This observation was gender-independent and is in line with existing knowledge on the influence of $\mathrm{CN}$ on amount of time spent in natural environments $[23,24]$. On the contrary, staying outdoors for the purpose of sunbathing as well as indoor tanning were not significant predictive factors for perceived level of $\mathrm{CN}$. Additionally, we did not reveal predictive potential for phenotype, i.e., skin type, and tanning behaviour-related aspects (occurrence of sunburn, SPF value, motives to tan, and sun protection).

It is commonly accepted understanding that green exercise, i.e., physical exercise whilst being exposed to natural environments, has positive effects on well-being. Additionally, Watson et al. showed that the lately booming urban and "guerrilla" gardening in Western countries, community as well as private gardening exerted various health-promoting outcomes including cardiovascular and restorative benefits [48]. Accordingly, spending $15 \mathrm{~min}$ in outdoor environments increased CN, attention span, and positive feelings through nature's vast interactions with the human socio-biology [49]. Also, besides primary and secondary preventive measures, green exercise could offer mood-stabilizing and activity-promoting opportunities in rehabilitative settings [50]. In the same verve, researchers showed that respective environmental education programs increased children's CN [51]. To comply with Public (Skin) Health demands, these programs should also comprise evidence-based educative information on effective photoprotective behaviours to reduce UV radiation-associated skin hazard [18].

Although natural spaces could offer plentiful resources for people's health promoting activities, there is a need to raise awareness on the potential health risks of staying outdoors, as recommended by Kamioka et al. [52]. This suggestion is based on the notion that in contrast to the vast amount of literature identifying advantages outcomes of spending time outdoors, potential skin risks have been neglected in investigations of physico-chemical, but also psycho-mental effects of exposure to green spaces [1]. For example, unprotected extensive outdoor sport activities like marathon running was reported to increase melanoma risk [53]. Further, occupational UV radiation exposure of outdoor workers was also shown to be a causative factor for all types of skin cancer [54]. Nevertheless, in contrast to lifestyle-associated sun exposure, e.g., for tanning purposes, photoprotective measures during work-related outdoor abidance are legally controlled by occupational medicine-related regulations [55]. 
Despite potential short- and long-term health risks, UV radiation exposure was promoted as a surplus benefit of intentional outdoor activities due to its potential to increase vitamin D blood levels. Respective recommendations are contradicting Public (Skin) Health promoting efforts aimed at reducing sun light exposure and could create confusion and reluctance in consumers and patients. These considerations should be integrated in the debate regarding encouragement of spending time outdoors in natural environments in order to enjoy the aforementioned merits on well-being.

As strength of this study, the current findings add to a growing body of literature on positive effects of nature that low and high levels of perceived $\mathrm{CN}$ differed in recreational outdoor activities. In synopsis with our findings on gender differences in regard of health risky behaviour (including solar protection and tobacco smoking), results of this survey contribute additional evidence that the conventional "one-size-fits-all" approach might not be the best way to successful skin health promotion strategies [56].

The findings in this report are subject to several limitations. First, a non-response bias could not be ruled out because participation in the study was voluntary and Austrian citizens that chose to answer the questionnaire may have been more concerned about their skin health or sun protective behaviour. Second, this survey assessed self-reported data introducing social desirability and recall bias. Nevertheless, recall bias regarding UV light exposure was shown to be quite small [57]. Third, dichotomization by means of median splits could have methodological consequences such as loss of information [58]. However, in a wide range of scientific disciplines, median split is a commonly used method for analysis of survey data. As we considered size and distribution of our study sample to allow for dichotomizing variables, we also applied this technique in the present survey. Last, causal relations between $\mathrm{CN}$ and sun-related behaviour could not be drawn due to the cross-sectional design of this survey. Nonetheless, contact with nature could create positive effects on well-being and thus could promote intentional activities to increase the time spent outdoors, leading to UV radiation exposure.

\section{Conclusions}

The results of this cross-sectional telephone survey among Austrian residents provide theoretical contributions to the understanding of the relationship between the construct connectedness to nature and skin health-related aspects. Further, a so far unrecognized overlap between environmental psychology and Public (Skin) Health was identified. Thus, we suggest interdisciplinary networks including various expert groups such as landscape architects, environmental psychologists, and medical professionals to further examine benefits and risks of recreational outdoor nature experiences.

\section{Acknowledgments}

This research work was partly funded by Klima- und Energiefonds Austria, Project "UVSkinRiskHealth at risk through UV induced Skin Cancer in the Context of a Changing Climate". We would like to thank the anonymous referees for helpful remarks. 


\section{Authors Contributions}

D.H. conceived the idea for and drafted the manuscript. S.S. and R.C and provided strategy for data analyses and interpretation. H.M. and J.H. collaborated to manuscript writing. All co-authors contributed with comments and revised the manuscript.

\section{Conflicts of Interest}

The authors declare no conflict of interest.

\section{References}

1. Bowler, D.E.; Buyung-Ali, L.M.; Knight, T.M.; Pullin, A.S. A systematic review of evidence for the added benefits to health of exposure to natural environments. BMC Public Health 2010, 10, doi:10.1186/1471-2458-10-456.

2. Mitchell, R.; Popham, F. Greenspace, urbanity and health: Relationships in England. J. Epidemiol. Community Health 2007, 61, 681-683.

3. De Vries, S.; Verheij, R.A.; Groenewegen, P.P.; Spreeuwenberg, P. Natural environmentsHealthy environments? An exploratory analysis of the relationship between greenspace and health. Environ. Plann. 2003, 35, 1717-1731.

4. Abraham, A.; Sommerhalder, K.; Abel, T. Landscape and well-being: A scoping study on the health-promoting impact of outdoor environments. Int. J. Public Health 2010, 55, 59-69.

5. Michimi, A.; Wimberly, M.C. Natural environments, obesity, and physical activity in nonmetropolitan areas of the United States. J. Rural Health 2012, 28, 398-407.

6. Groenewegen, P.P.; van den Berg, A.E.; de Vries, S.; Verheij, R.A. Vitamin G: Effects of green space on health, well-being, and social safety. BMC Public Health 2006, 6, doi:10.1186/14712458-6-149.

7. Kricker, A.; Armstrong, B.K.; Goumas, C.; Litchfield, M.; Begg, C.B.; Hummer, A.J.; Marrett, L.D.; Theis, B.; Millikan, R.C.; Thomas, N.; et al. Ambient UV, personal sun exposure and risk of multiple primary melanomas. Cancer Causes Control 2007, 18, 295-304.

8. Haluza, D.; Kaiser, A.; Moshammer, H.; Flandorfer, C.; Kundi, M.; Neuberger, M. Estimated health impact of a shift from light fuel to residential wood-burning in Upper Austria. J. Expo. Sci. Environ. Epidemiol. 2012, 22, 339-343.

9. Serandour, J.; Girel, J.; Boyer, S.; Ravanel, P.; Lemperiere, G.; Raveton, M. How human practices have affected vector-borne diseases in the past: A study of malaria transmission in alpine valleys. Malar. J. 2007, 6, doi:10.1186/1475-2875-6-115.

10. Dennis, L.K.; Vanbeek, M.J.; Freeman, L.E.B.; Smith, B.J.; Dawson, D.V.; Coughlin, J.A., Sunburns and risk of cutaneous melanoma: Does age matter? A comprehensive meta-analysis. Ann. Epidemiol. 2008, 18, 614-627.

11. Jemal, A.; Saraiya, M.; Patel, P.; Cherala, S.S.; Barnholtz-Sloan, J.; Kim, J.; Wiggins, C.L.; Wingo, P.A. Recent trends in cutaneous melanoma incidence and death rates in the United States, 1992-2006. J. Am. Acad. Dermatol. 2011, 65, S17.e1-S17.e11. 
12. Guy, G.P.; Ekwueme, D.U. Years of potential life lost and indirect costs of melanoma and non-melanoma skin cancer: A systematic review of the literature. PharmacoEconomics 2011, 29, 863-874.

13. Kittler, H.; Binder, M.; Wolff, K.; Pehamberger, H. A ten-year analysis of demographic trends for cutaneous melanoma: Analysis of 2501 cases treated at the University Department of Dermatology in Vienna (1990-1999). Wien. Klin. Wochenschr. 2001, 113, 321-327.

14. Dos Santos Silva, I.; Higgins, C.D.; Abramsky, T.; Swanwick, M.A.; Frazer, J.; Whitaker, L.M.; Blanshard, M.E.; Bradshaw, J.; Apps, J.M.; Bishop, D.T.; et al. Overseas sun exposure, nevus counts, and premature skin aging in young English women: A population-based survey. J. Invest. Dermatol. 2009, 129, 50-59.

15. Yam, J.C.S.; Kwok, A.K.H. Ultraviolet light and ocular diseases. Int. Ophthalmol. 2013, 2013, doi:10.1007/s10792-013-9791-x.

16. Glanz, K.; Yaroch, A.L.; Dancel, M.; Saraiya, M.; Crane, L.A.; Buller, D.B.; Manne, S.; O'Riordan, D.L.; Heckman, C.J.; Hay, J.; et al. Measures of sun exposure and sun protection practices for behavioral and epidemiologic research. Arch. Dermatol. 2008, 144, 217-222.

17. Boogerd, W.; de Gast, G.C.; Dalesio, O. Temozolomide in advanced malignant melanoma with small brain metastases: Can we withhold cranial irradiation? Cancer 2007, 109, 306-312.

18. Haluza, D.; Cervinka, R. Perceived relevance of educative information on public (skin) health: A cross-sectional questionnaire survey. J. Prev. Med. Public Health 2013, 46, 82-88.

19. Haluza, D.; Cervinka, R. Public (Skin) health and the publishing source bias of austrian information material. Cent. Eur. J. Med. 2013, 2013, doi:10.2478/s11536-013-0246-6.

20. Gosling, E.; Williams, K.J.H. Connectedness to nature, place attachment and conservation behaviour: Testing connectedness theory among farmers. J. Environ. Psychol. 2010, 30, 298-304.

21. Mckechnie, G.E. The environmental response inventory in application. Environ. Behav. 1977, 9, 255-276.

22. Nisbet, E.K.; Zelenski, J.M. The NR-6: A new brief measure of nature relatedness. Front Psychol. 2013, 4, doi:10.3389/fpsyg.2013.00813.

23. Hinds, J.; Sparks, P. Engaging with the natural environment: The role of affective connection and identity. J. Environ. Psychol. 2008, 28, 109-120.

24. Cervinka, R.; Roderer, K.; Hefler, E. Are nature lovers happy? On various indicators of wellbeing and connectedness with nature. J. Health Psychol. 2012, 17, 379-388.

25. Haluza, D.; Simic, S.; Moshammer, H. Temporal and spatial melanoma trends in austria: An ecological study. Int. J. Environ. Res. Public Health 2014, 11, 734-748.

26. Groves, R.M. Nonresponse rates and nonresponse bias in household surveys. Public Opin. Q. 2006, 70, 646-675.

27. Fitzpatrick, T.B. The validity and practicality of sun-reactive skin types I through VI. Arch. Dermatol. 1988, 124, 869-871.

28. Irwin, B.; Mauriello, D.; Hemminger, L.; Pappert, A.; Kimball, A.B. Skin sun-acne tutorial evaluation among middle- and high-school students in central New Jersey. J. Am. Acad. Dermatol. 2007, 56, 407-412. 
29. Rouhani, P.; Parmet, Y.; Bessell, A.G.; Peay, T.; Weiss, A.; Kirsner, R.S. Knowledge, attitudes, and behaviors of elementary school students regarding sun exposure and skin cancer. Pediatr. Dermatol. 2009, 26, 529-535.

30. Feher, K.; Cercato, M.C.; Prantner, I.; Dombi, Z.; Burkali, B.; Paller, J.; Ramazzotti, V.; Sperduti, I.; Nadasi, E.; Parragi, K.; et al. Skin cancer risk factors among primary school children: Investigations in western hungary. Prev. Med. 2010, 51, 320-324.

31. Hooley, J.M.; Siegle, G.; Gruber, S.A. Affective and neural reactivity to criticism in individuals high and low on perceived criticism. PLoS One 2012, 7, doi:10.1371/journal.pone.0044412.

32. Elder, J.P.; Castro, F.G.; de Moor, C.; Mayer, J.; Candelaria, J.I.; Campbell, N.; Talavera, G.; Ware, L.M. Differences in cancer-risk-related behaviors in Latino and Anglo adults. Prev. Med. 1991, 20, 751-763.

33. Koster, B.; Thorgaard, C.; Clemmensen, I.H.; Philip, A. Sunbed use in the Danish population in 2007: A cross-sectional study. Prev. Med. 2009, 48, 288-290.

34. de Haas, E.R.; Nijsten, T.; de Vries, E. Population education in preventing skin cancer: from childhood to adulthood. J. Drugs Dermatol. 2010, 9, 112-6.

35. Kasparian, N.A.; McLoone, J.K.; Meiser, B.: A review of the literature. J. Behav. Med. 2009, 32, 406-428.

36. Heckman, C.J.; Darlow, S.; Cohen-Filipic, J.; Kloss, J.D.; Manne, S.L.; Munshi, T.; Perlis, C.S. Psychosocial correlates of sunburn among young adult women. Int. J. Environ. Res. Public Health 2012, 9, 2241-2251.

37. Lawler, S.; McDermott, L.; O’Riordan, D.; Spathonis, K.; Eakin, E.; Leslie, E.; Gallois, C.; Berndt, N.; Owen, N. Relationships of sun-protection habit strength with sunscreen use during outdoor sport and physical activity. Int. J. Environ. Res. Public Health 2012, 9, 916-923.

38. Oliveria, S.A.; Saraiya, M.; Geller, A.C.; Heneghan, M.K.; Jorgensen, C. Sun exposure and risk of melanoma. Arch. Dis. Child 2006, 91, 131-138.

39. Veierod, M.B.; Adami, H.O.; Lund, E.; Armstrong, B.K.; Weiderpass, E. Sun and solarium exposure and melanoma risk: Effects of age, pigmentary characteristics, and nevi. Cancer Epidemiol. Biomarkers Prev. 2010, 19, 111-120.

40. Sneyd, M.; Cox, B. The control of melanoma in New Zealand. N.Z. Med. J. 2006, 119, 1242.

41. Saroglou, V.; Buxant, C.; Tilquin, J. Positive emotions as leading to religion and spirituality. J. Posit. Psychol. 2008, 3, 165-173.

42. Tam, K.-P. Concepts and measures related to connection to nature: Similarities and differences. J. Environ. Psychol. 2013, 34, 64-78.

43. Dutcher, D.D.; Finley, J.C.; Luloff, A.E.; Johnson, J.B. Connectivity with nature as a measure of environmental values. Environ. Behav. 2007, 39, 474-493.

44. Thompson, C.A.; Waldhor, T.; Schernhammer, E.S.; Hackl, M.; Vutuc, C.; Haidinger, G. Smoking and lung cancer: Current trends in austria. Wien. Klin. Wochenschr. 2012, 124, 493-499.

45. Kennedy, R.D.; Behm, I.; Craig, L.; Thompson, M.E.; Fong, G.T.; Guignard, R.; Beck, F. Outdoor smoking behaviour and support for outdoor smoking restrictions before and after france's national smoking ban. Eur. J. Public Health 2012, 22, 29-34. 
46. Guiterrez-Bedmar, M.; Segui-Gomez, M.; Gomez-Gracia, E.; Bes-Rastrollo, M.; Martinez-Gonzalez, M.A. Smoking status, changes in smoking status and health-related quality of life: Findings from the sun ("seguimiento universidad de navarra") cohort. Int. J. Environ. Res. Public Health 2009, 6, 310-320.

47. Disentangling Complex Relationships: The Role of Time Spent in Nature. Available online: http://www.psi-ambiental.net/pdf/a-iaps/KathrinRoederer.pdf (accessed on 12 October 2013).

48. Watson, D.L.B.; Moore, H.J. Community gardening and obesity. Perspect. Public Health 2011, 131, 163-164.

49. Mayer, F.S.; Frantz, C.M.; Bruehlman-Senecal, E.; Dolliver, K. Why is nature beneficial? The role of connectedness to nature. Environ. Behav. 2009, 41, 607-643.

50. Barton, J.; Griffin, M.; Pretty, J. Exercise-, nature- and socially interactive-based initiatives improve mood and self-esteem in the clinical population. Perspect. Public Health 2012, 132, 89-96.

51. Ernst, J.; Theimer, S. Evaluating the effects of environmental education programming on connectedness to nature. Environ. Educ. Res. 2011, 17, 577-598.

52. Kamioka, H.; Tsutani, K.; Mutoh, Y.; Honda, T.; Shiozawa, N.; Okada, S.; Park, S.J.; Kitayuguchi, J.; Kamada, M.; Okuizumi, H.; et al. A systematic review of randomized controlled trials on curative and health enhancement effects of forest therapy. Psychol. Res. Behav. Manag. 2012, 5, 85-95.

53. Ambros-Rudolph, C.M.; Hofmann-Wellenhof, R.; Richtig, E.; Muller-Furstner, M.; Soyer, H.P.; Kerl, H. Malignant melanoma in marathon runners. Arch. Dermatol. 2006, 142, 1471-1474.

54. Young, C. Solar ultraviolet radiation and skin cancer. Occup. Med. 2009, 59, 82-88.

55. Milon, A.; Bulliard, J.L.; Vuilleumier, L.; Danuser, B.; Vernez, D. Estimating the contribution of occupational solar ultraviolet exposure to skin cancer. Br. J. Dermatol. 2014, 170, 157-164.

56. Day, A.K.; Oxlad, M.; Roberts, R.M. Predictors of sun-related behaviors among young women: Comparisons between outdoor tanners, fake tanners, and tan avoiders. J. Am. Coll. Health 2013, 61, 315-322.

57. Parr, C.L.; Hjartaker, A.; Laake, P.; Lund, E.; Veierod, M.B. Recall bias in melanoma risk factors and measurement error effects: A nested case-control study within the Norwegian women and cancer study. Am. J. Epidemiol. 2009, 169, 257-266.

58. MacCallum, R.C.; Zhang, S.; Preacher, K.J.; Rucker, D.D. On the practice of dichotomization of quantitative variables. Psychol. Methods 2002, 7, 19-40.

(C) 2014 by the authors; licensee MDPI, Basel, Switzerland. This article is an open access article distributed under the terms and conditions of the Creative Commons Attribution license (http://creativecommons.org/licenses/by/3.0/). 